\title{
Problem Analysis and Countermeasures in the Development of Red Tourism
}

\author{
Yunli Shi \\ Primary Education College, Linyi University, Feixian, Shandong, China \\ 15165519838@163.com
}

Keywords: Red tourism; Development; Image; Countermeasure

\begin{abstract}
The development of red tourism of the city should be promoted to a higher level of shaping the brand image and marketing the concept of red culture form in the ordinary level of advertising tourism resources and selling tourism products. The paper puts forward some countermeasures to the subsequent development of red tourism through the analysis of the problems existing in the following-up development of Linyi red tourism.
\end{abstract}

\section{Introduction}

Red tourism fervor has been boomed since the official issue and implementation of 2004-2010 National Red Tourism Development Planning Outline in February 22, 2005, and red tourism also hasten to mature. The level of red tourism development rises continuously and the government promotes the development of red tourism integration as a whole, launches a batch of choices tour of revolutionary heritage rich in connotation and great distinction. Under the guidance of scientific development concept, constructing "tourism economy strong city, red tourism city" as the goal, Linyi tourism speeds up project constructions, improves the infrastructure, strengthens the propaganda promotion and standardizes management of the industry, which help tourism take on good development momentum. Red tourism plays a positive role in strengthening patriotism political education and promoting economic development of old revolutionary areas.

The focus of the development of the following-up red tourism is the "whole tourist place and its tourism products", and the main purpose is to raise its popularity and image. Only through using its influence, rationally mobilizing the effective resources and actively promoting the red tourism image can the government and the tourist enterprises enhance the attraction of the tourism destination. If red tourism wants to receive better economic and social benefits, the emphasis of the government and the tourism enterprises should be put correctly in its respective operation. Only in this way can tourism marketing form an ordered, three-dimensional, reasonable and efficient mechanism.

\section{Present Situation of Linyi Red Tourism Products}

Linyi has a long history and profound culture with a diversity of red tourism resources widely distributed where rich in connotation, known by travel experts as the "two war shrine" (the Anti-Japanese War and the Liberation War). In modern history of China, Yimen revolutionary area has the similar fame with Jinggangshan, Yan'an, Taihang mountains and Dabie mountains, which is one of the five famous revolutionary areas in the country. During the Anti-Japanese War and the Liberation War, Yimen is a famous revolutionary base area, the capital of the liberated areas in Shandong and revolutionary struggle commanding hub in East China with a large number of revolutionary relics. The stories of "Yimeng Mothers", "Yimeng Revolutionary Sisters-in-law", and "Yimeng six sisters" passed down from generation to generation.

In the spring of 1927, the first party branch in Yimeng mountain area---the Chinese Communist Party branch of Yishui established. In 1938, according to the new situation of the national revolutionary war after the outbreak of Anti-Japanese War, the CPC central committee sent Xu xiangqian and Luo Ronghuan to lead the 8th Route Army 115 Division into Shandong, opened the 
Yimeng revolutionary base area. From then to the liberation of the country, Yimeng mountain area, as the headquarters of the Eighth Route Army 115 Division, Shandong branch of the central committee of the communist party of China, East China bureau of the New Fourth Army and the central committee of the Communist Party of China, East China military region, East China field army, the people's government of Shandong Province, became commanding hub in East China and the national famous revolutionary base areas, known as "Yan'an in East China". On this heroic land, relics of older generation of revolutionaries and leaders of the battle and works were left, such as $\mathrm{Xu}$ Xiangqian, Luo Ronghuan, Chen Yi, Liu Shaoqi, SuYu, XiaoHua and Gu Mu etc. There are two national patriotism education bases, thirteen provincial patriotism education bases and thirty-six city patriotism education bases in Linyi.

\section{Problems Existing in the Development of Linyi Red Tourism}

There are still many difficulties and problems existing in the development of Linyi tourism, which mainly displays in the following aspects: the system and mechanism of accelerating the development of tourism industry are still not smooth; external publicity of most of the red tourist areas don't have concerted and unified action, resulting in the weakening of the power of propaganda; red culture connotation lack digging, and the function of tourism products is single; the scale of tourism industry is small; comprehensive function is not strong; tourism markets are narrow; the role of city tourism destination has not yet been fully revealed; tourism receptive facilities are still not enough. In general, the solution of these problems needs to improve the depth of the development of red tourism industry in China in the process of pushing industrialization and marketization of red tourism.

Tourism Image Positioning is Fuzzy and Brand Image Publicity is not Enough. Tourism image orientation should be around the core competitiveness and accelerate the development of the tourism products system. Around the six themes of "green amorous feelings, red Yimeng, military strategy, geological wonders, waterside city and commercial capital, spring resort and healthcare", Linyi constantly accelerates the construction of tourism projects, gradually improves the tourism product system, and makes efforts to improve the core competitiveness of tourism. From the original "good places of Yimeng mountain areas" to "natural landscape, affection Yimeng" to "landscape Yimeng, commercial Linyi" in 2010, the establishment of tourism image is still not very clear.

The Government Marketing Budget is Limited and the Marketing Combination of Politics Enterprise is not Enough. Governments of each county in Linyi city have made the budget on the red tourism resources development, but marketing budget in the red tourism is not yet clear and always gives priority to tourism enterprises in the tourism marketing. Yishui with rapid development of red tourism, as the tourism county, awarded with "China excellent tourism destination" by the first China tourism marketing annual meeting also takes the joint stock system and other forms, fully in accordance with the market-oriented operation. Its financial support is not fully revealed. In specific operations, adhering to government-leading marketing and setting up the tourism promotion fund, Yishui organizes marketing activities led by government and participated by the principals of tourism administrations, the scenic spot and travel agency over 3 times every year, aiming to obtain a good regional tourism brand effect as a whole.

Poverty Alleviation and Enriching People Drive Poorly and the Potential Development Don't be Fully Dug out. Red tourism is in line with the modern regional anti-poverty theory, because the core of tourism poverty alleviation strategy target should make the poor own the opportunity and ability of getting rid of poverty through the development of tourism to the greatest extent through the development of pro-poor tourism economy. There are still many characteristics of the lagging-behind of development and low-level economic base due to reasons of history, concept, location and transportation, which urgently needs to set out from its own conditions, gradually broaden the thought and seek more effective innovation and development path under the support of national and local government. Red tourism has, in fact, explored this kind of way and gained valuable experience and good social and economic benefits, such as Meng Lianggu tourist area, Yimeng revolutionary base 
and other red tourism scenic areas have developed red tourism classic scenic spots, branded their own characteristics and drove the breakthrough of the development. But as a project to enrich the people, the potential of helping people in old and new border areas develop social economics hasn't been dug out fully.

\section{Countermeasures and Suggestions of the Subsequent Development of Red Tourism}

The construction of "Resource-conserving \& environmental-friendly society" requires the red tourism industry to improve resource utilization, attach great importance to the tourism experience, enhance regional competitiveness and realize the sustainable development of red tourism through the establishment of brand image, the integration of red tourism culture resources and sufficient political advantage.

Brand Image Positions Clearly and Pays Attention to the Planning of the System as a Whole.

Firstly, the "red Yimeng, landscape mall" as the positioning of red tourism image.

There are a large amount of tourism areas in South Shandong, North China and the red tourism scenic area construction increases continuously, which has led to a boom of tourist information. The idea of "Yimen revolutionary area", "Yimeng good place" and "revolutionary areas" will spring in tourists' mind when mentioning Linyi. In terms of history and culture, the idea of "hometown of Wang Xizhi", "the bamboo slips analects" and "birthplace of Dongyi culture" will, in turn, appear in the mind of tourists. In terms of natural scenery, Mengshan and Yishui underground grand canyon, etc will be the representatives.

As red tourism, government should pay more attention to the core value of products. About the brand positioning of red tourism by refining the core value, the author believes that we should position "red Yimen, landscape mall" as a red tourism image (and even the Linyi tourism image).

Secondly, red tourism brand is established in the strategy of "SSSS".

Famous marketing experts Lu Changquan pointed out that: all brand competition is not a "product" competition, but a battle of obtaining consumers' cognition and their hearts. Tourism enterprises can build up their brands fame through the high and low cost operation these two ways. High cost operation mainly informs widely through television advertisements and quickly establishes brand awareness. Low cost way makes consumers or customers activated in every link of information through the clear and strong difference show, product show, ranking show and feeling show, forms an effective cognitive purchase and establish brand in the strategy of "SSSS".

Thirdly, planning attaches great importance to the integration and innovation to improve the core value of "red Yimeng, landscape mall".

Before the development of the red tourism culture resources and the subsequent development, it is necessary to have an overall system, detailed and careful planning to the tourism resources and construction. Regulation can make a scientific layout to the hardware and software resources, and planning can make an accurate market analysis, market positioning and market segmentation. Systematic regulation and planning can effectively avoid redundant construction. The government in Yishui, Shandong, in order to build the tourism culture brand of "Yimeng revolutionary base", specially invited famous planners to make an overall planning of cultural tourism development, from the hardware resources of the hotel, transportation, real estate industry to the software resources of the Yimeng culture, shopping and rural ecological tourism. From the overall perspective, they systematically plan tourism resource with the property of software and hardware and provide feasibility basis for subsequent development.

\section{Differentiated Marketing Through Integration of Cultural Resources.}

Firstly, characteristic culture as the staple and emphasis on the recessive marketing.

A red tourism scenic area can have a variety of culture, but must have its main characteristics. Literatures and film works with subtle influences don't not hammer into the heads of the audiences but attracted by the plot of the story, subtly influence them on the scene of the story in audience's mind to provoke their strong desire to experience on the spot or visit it; with wide coverage of 
information, the influence of good works itself can almost cover every corner of the world, while information coverage is unmatched with any other medias. Government in red tourism destinations should actively cooperate with filmmakers, using movies this particular information media, and demonstrate the unique charming of a tourist destination, so as to achieve the purpose of tourism destination awareness to expand its influence.

Secondly, meet consumers' demands and integrate tourism resources

Red culture tourism resources of scenic spots not only have the advantages of richness and diversity, but also the disadvantages of narrow tourist resource market. In order to market tourism products better, it is a good idea if we make their respective advantages complementary each other, have the integration of culture resources and improve the quality of tourism products. The development of tourism scenic area must shift from a single relying on cultural relics to relying on culture, and then further basing on the traveling scenic area culture resources.

Thirdly, making use of festival activities have differentiated marketing.

Since 2003, Linyi built festival and meeting brands, formed a cultural landscape of "Zhu Geliang in Spring, Wang Xizhi in Autumn", vigorously constructed tourism and culture facilities and formed a good situation of city, county and grass-roots synchronous development, not only attracting a large number of tourists, but effectively playing the role of establishing the publicity of tourist destination image. Secondly, we can take advantage of the films and televisions tourism and leisure entertainment for publicity and marketing. Linyi won three national classical awards in 2009: large-scale water performance played outdoor edition: Mengshan and Yishui River, film Six Sisters in Yimeng, and TV play series Yimeng with 42, which swept red hurricanes one after another, and made an "Yimen" unprecedented loud.

\section{Play Politics and Location Advantages and Make Experience Travel.}

Firstly, play political advantage and make big public consumption market.

From the market point of view, all sorts of units have political needs, including the communist party organs and the enterprise groups. On the Party's major activities, they would have to go to nearby red tourist areas. The historical and cultural background of Linyi red tourism made clearer target markets: that is, the political study tour groups which belong to national and non-state institutions and institutions of public spending. Facing the public consumption market, we must put in a lot of effort in project core appeal, base on the red cultural heritage protection, promote the vitality, fresh, and the depth of red tourism products, at the same time avoid the oneness of red tourism products, through enriching green scenic spots, the folk cultural attractions, recreation projects, etc., build up the concept of a comprehensive tourist area like Meng Lianggu and realize the supporting functions of attracting tourists.

Secondly, strengthen regional tourism cooperation with the aid of location advantage.

Strengthen cooperation with neighboring red tourist attractions, actively explore tourist markets. Linyi city is rich in tourism resources; relatively mature scenic areas developed by the government are less. As a result, the red tourism should synchronize with landscape tourism, ecological tourism, cultural tourism, border tourism, forest tourism and folk tourism, etc., which should be complementary and achieve harmonious development. Form a frame of big tourism destination through the binding of periphery tourism destinations and arrange more than one tourism line according to different customer market to achieve the result of the integration of red tourism and green tourism at public expense payment and visiting a few tourist destinations. Among them, the binding marketing of Linyi, Zaozhuang, Laiwu and Jiangsu Huaiyin (i.e. the original Yimeng revolutionary base) is of great significance.

Thirdly, attach great importance to the experience tourism and innovate path to further development

The key to improve red tourism attraction is to transform displaying the ordinary red cultural relics, namely "cultural relics tourism" into "cultural tourism" in the core of a red life experience during the revolutionary period, form a participatory and experiential tourism mode on the basis of the situation, truly realize tourism through entertainment and affection, experience life in red situation and 
recreational amusement in the red context to let red tourism works follow the innovative development mode of letting tourists transform from passive sightseeing to active participation and experience, such as a revolutionary life experience in interactive activities, large scene plays or large scene of songs and dances, large simulation actual combat performances, etc., to complete the red tourism's transformation from static to dynamic, from rigid to living, from sightseeing to experience. Through restoring red artistic conception, make red environment, form red atmosphere and form red life to achieve the result of red experience, so as to improve the grade of the red tourism products.

\section{Conclusion}

Catch the important opportunity of the first year of $13^{\text {th }}$ Five Year Plan, with "red flag flying in Yimeng" as the theme, launch tourism products of "walking in Yimeng, viewing the holy place, visiting red sisters-in-law" with the content of folk custom tourism in the home of red sisters-in-law, ecological tourism, shopping tourism, picking-up tourism, etc, organize series of red tourism theme promotion activities, make preparations for the seminar of "Liu Shaoqi and Yimeng revolutionary base", open the Yimeng red tourism network, edit and publish series of classic comic books, produce Yimeng revolutionary songs' CD and gain fame and success in the aspect of "tourism in the home of red sisters-in-law" brand. Through red tourism experience, "red Yimeng, landscape mall" brand image could become a driving force for the sustainable development of red tourism of Linyi.

\section{Reference}

[1] Shi Yunli. Research on the exploration and utilization of red tourism resources in Linyi[J]. Modern Business Trade Industry. 2011(5)

[2] Shi Yunli. Construction and spread of Linyi tourism brand based on the advantage of culture resources[J]. China Business \& Trade. 2011(10)

[3] Shi Yunli. Strategy research of the preservation and development of history and culture in south Shandong[J]. China Urbanization. 2011(2)

[4] Shi Yunli. Research on red tourism marketing strategy based on government level[J]. China Business \& Trade. 2011(5)

[5] Lu Ligang, Shi Yuzhu. Development of red tourism in the view of scientific development concept[J]. Truth Seeking. 2010(3)

[6] Xu Renlu. Strategy research of development in red tourism international market[J]. Economist. 2010(5)

[7] Shi Yunli. Tourists' perceptual evaluation to tourism destinations and influence on re-visiting strategy[J]. China Business \& Trade. 2011(11)

[8] Liu Xintian. Experiential development: option of sustainable development of red tourism[J]. Commercial Research. 2010(1)

[9] Liu Jianping, Zou Yan. Development of red tourism scenic sightseeing agriculture in Shaoshan[J]. Journal of Hunan University. 2010 (4)

[10]Wang Kongjing. Integration and collaborative development of the red tourism in Hunan-Hebei-Chongqing-Guangzhou border regions[J]. Guizhou Ethnic Studies ,2006(4) 